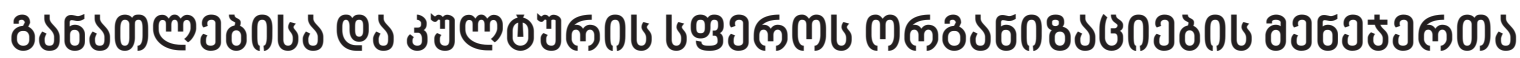

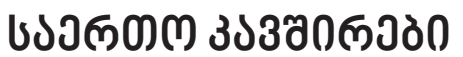

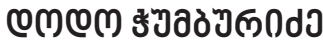

https://doi.org/10.35945/gb.2017.04.023

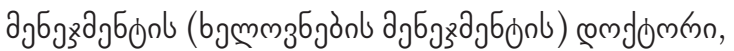

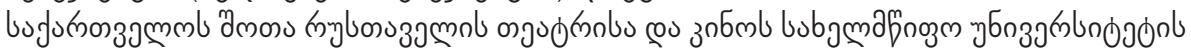

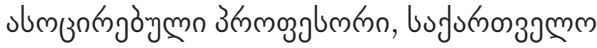

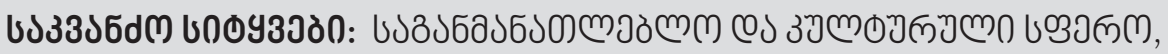

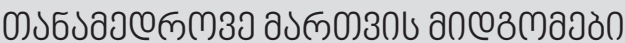

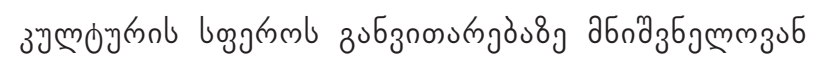

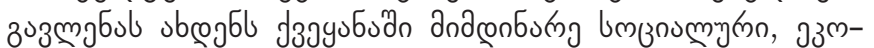

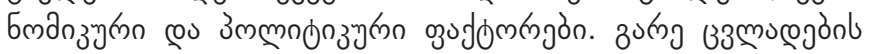

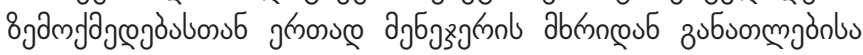

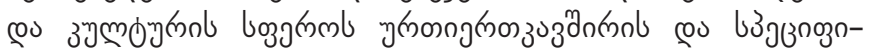

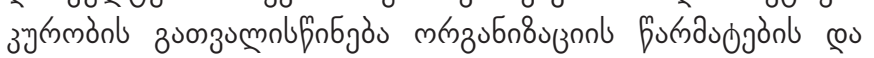

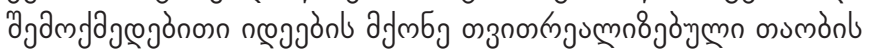

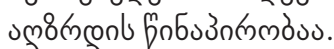

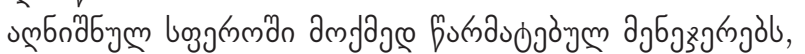

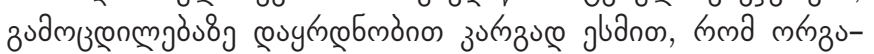

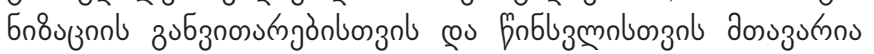

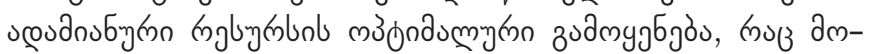

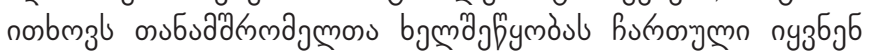

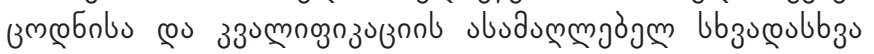

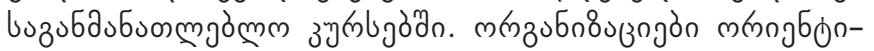

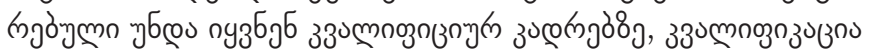

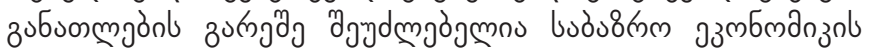

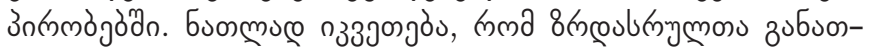

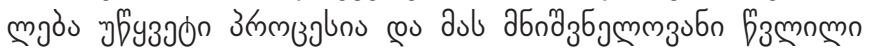

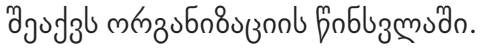

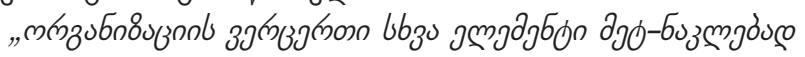

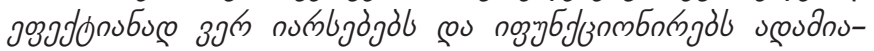

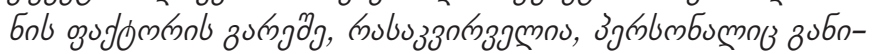

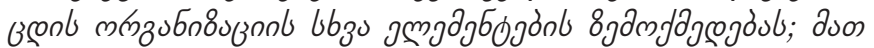

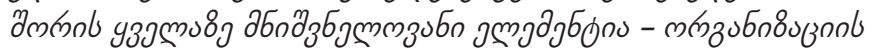

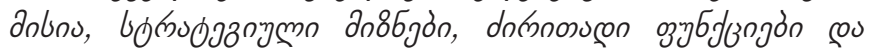

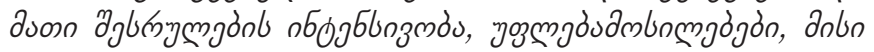

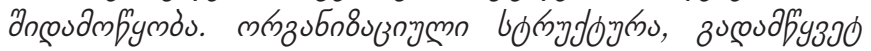

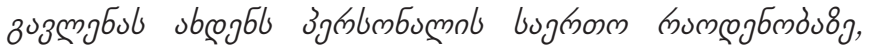

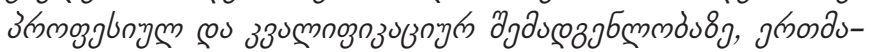

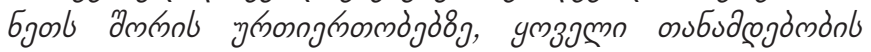

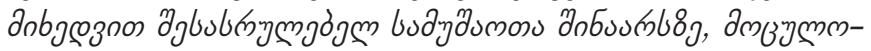

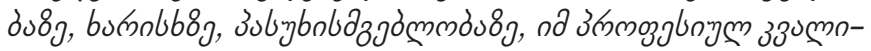

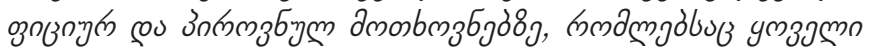

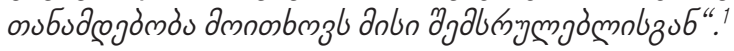

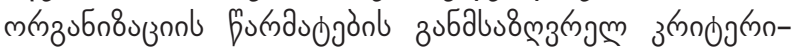

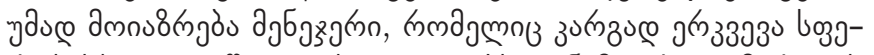

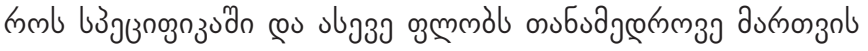

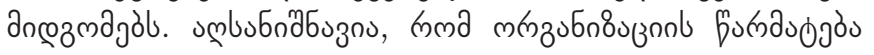

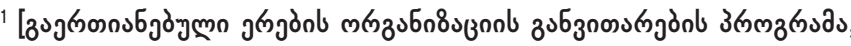

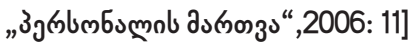

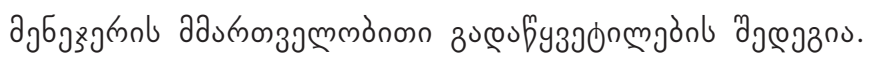
aduknoszammónonn zu

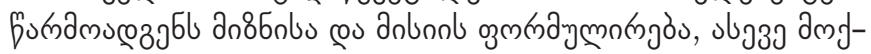

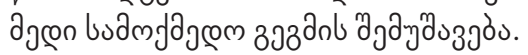

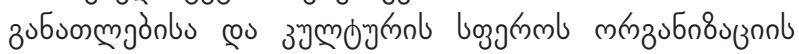

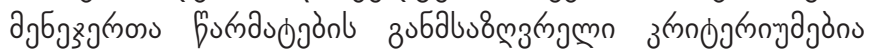

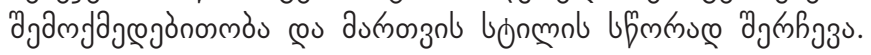

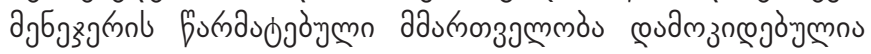

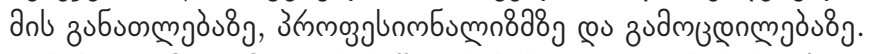

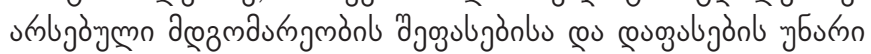

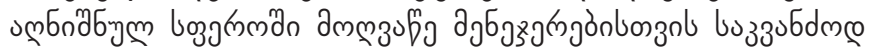

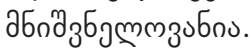

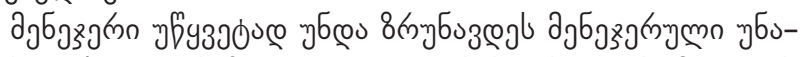

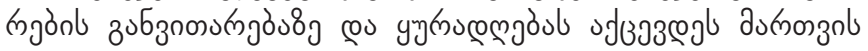

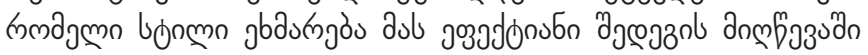

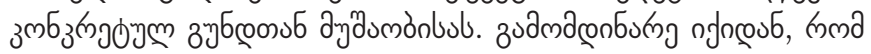

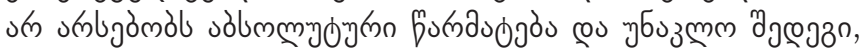

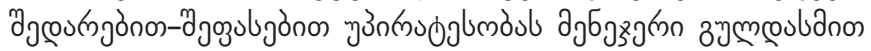

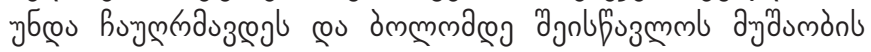

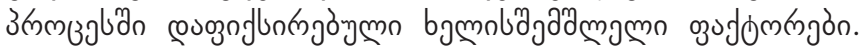

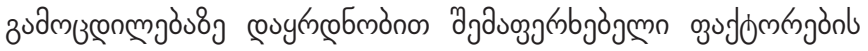

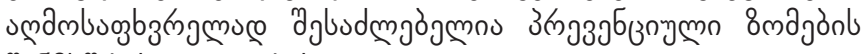

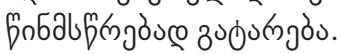

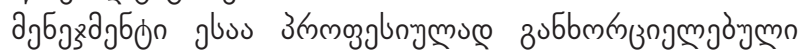

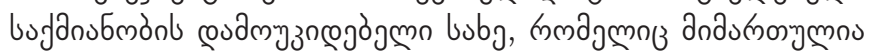

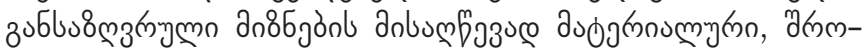

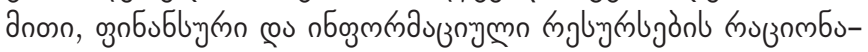

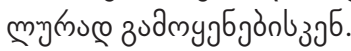

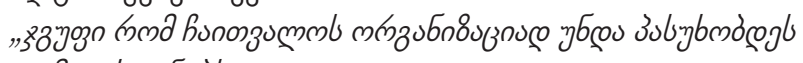

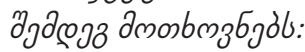

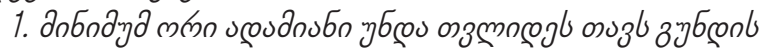

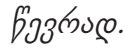

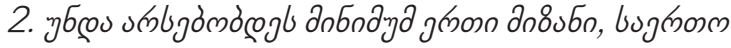

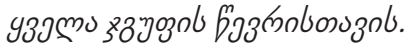

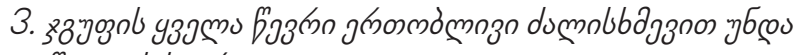

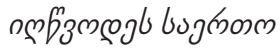

an86nl ansf63obuonzol".

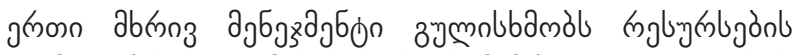

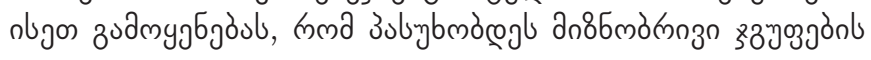

2 [Мескон, Альберт, Хедоури, „Основы Метеджмента“, 2012:23] 


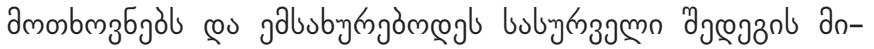

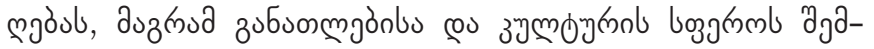

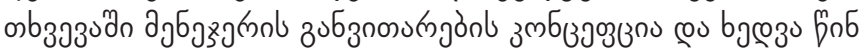

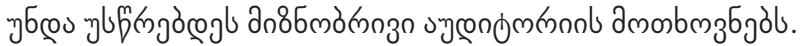

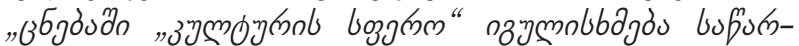

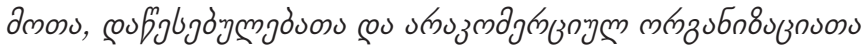

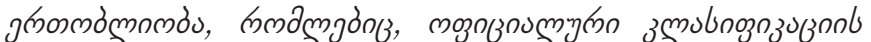

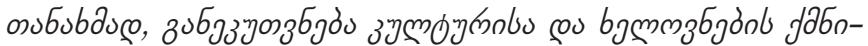

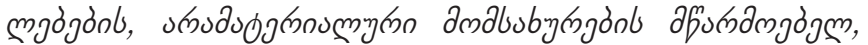

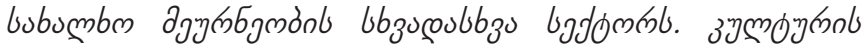

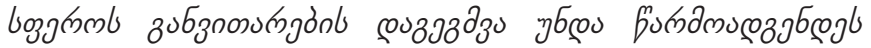

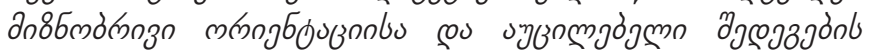

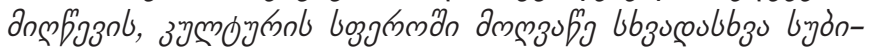

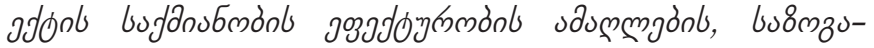

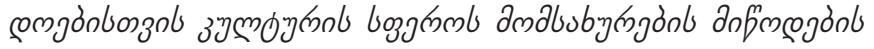

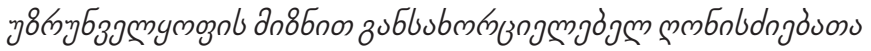

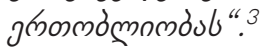

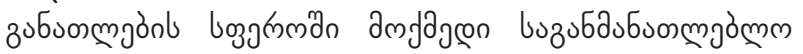

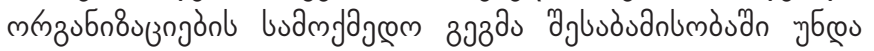

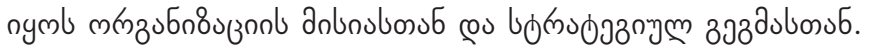

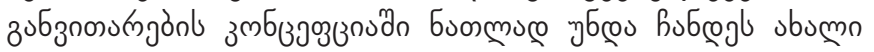

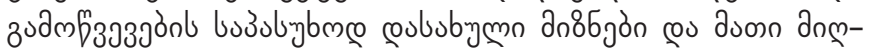

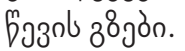

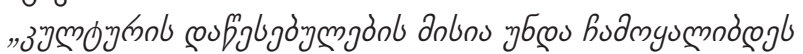

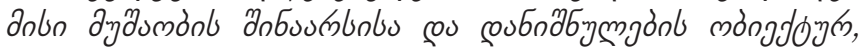

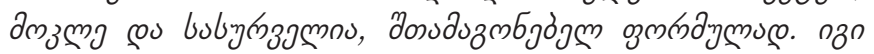

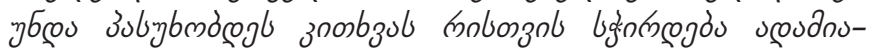

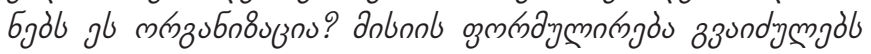

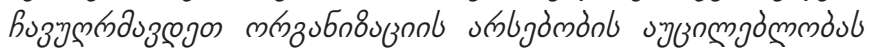

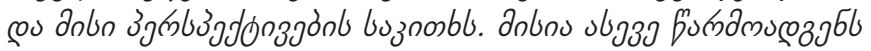

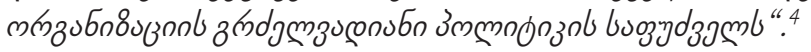

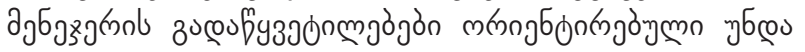

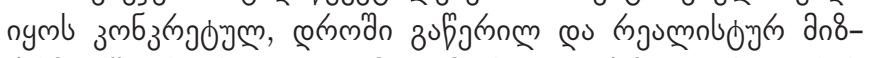

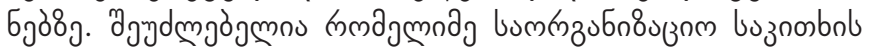

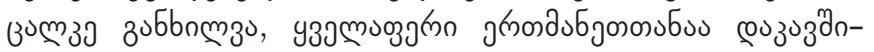

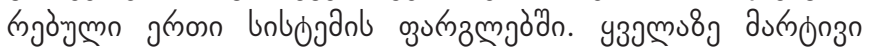

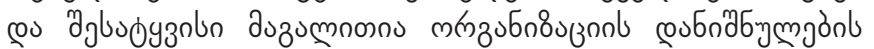
zublus

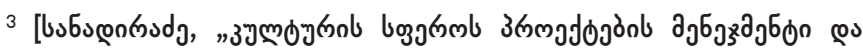

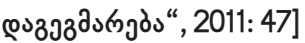

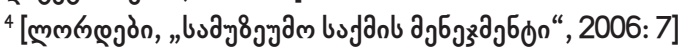

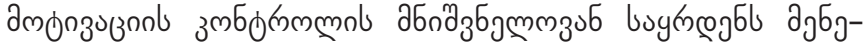

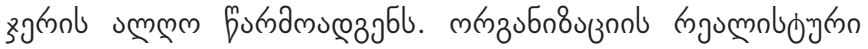

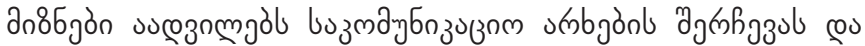

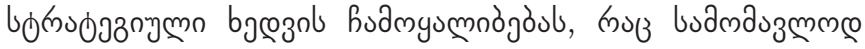

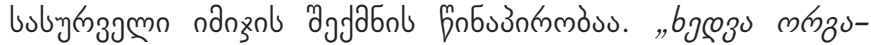

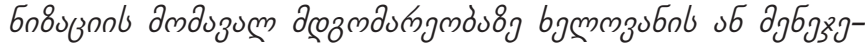

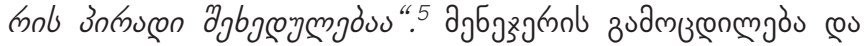

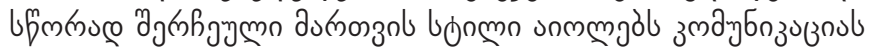

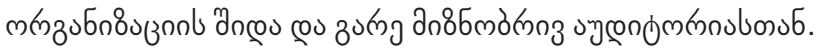

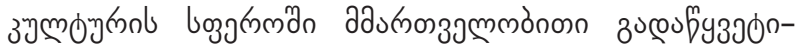

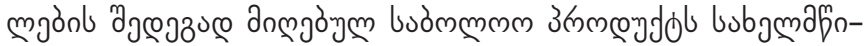
өзмgónnz

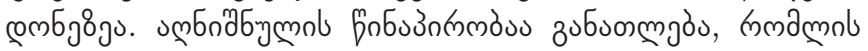

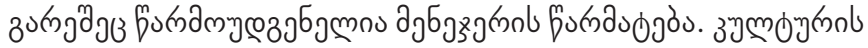

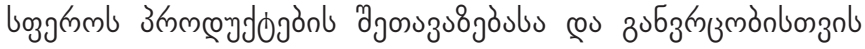

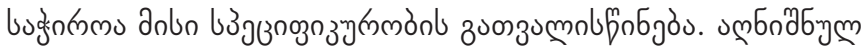

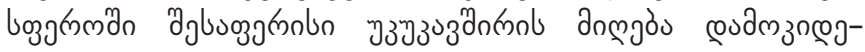

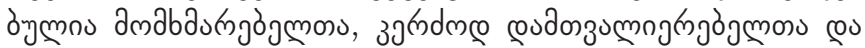

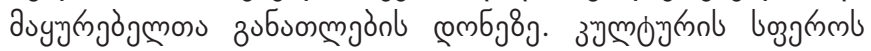

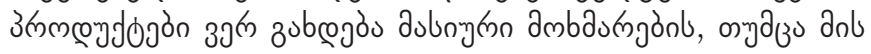

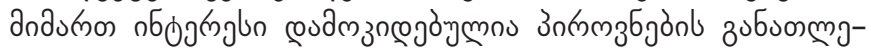

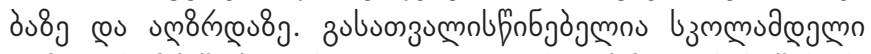

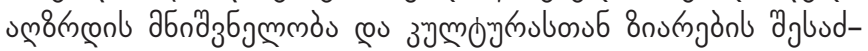

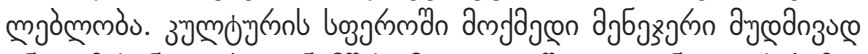

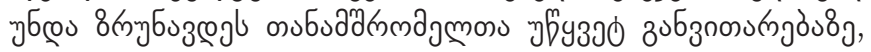

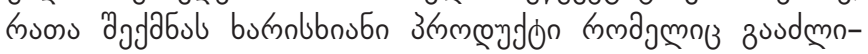

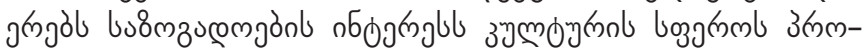

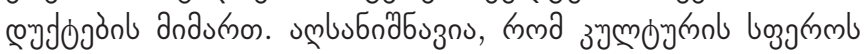

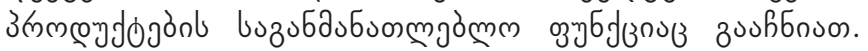

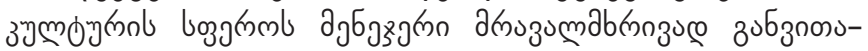

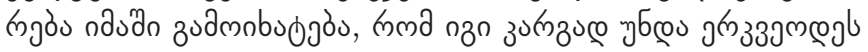

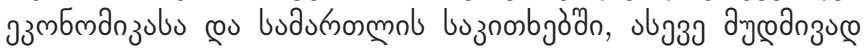

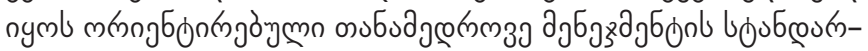

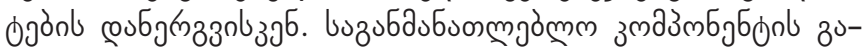

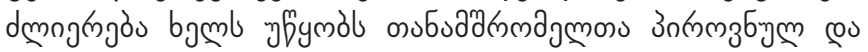

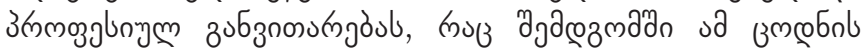

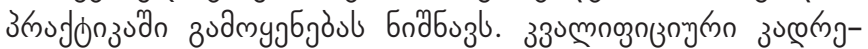

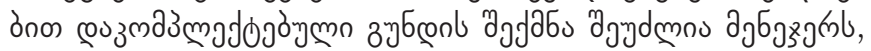

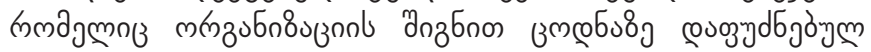

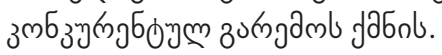

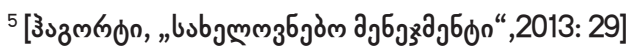

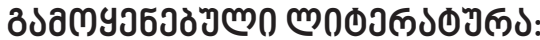

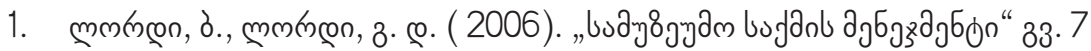

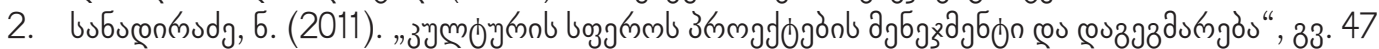

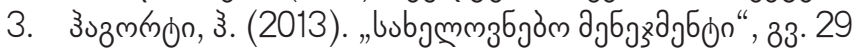

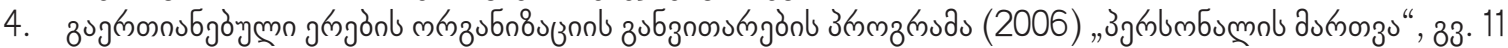

5. Мескон Х., Альберт М., ХедоуриФ., (2012), „Основы Метеджмента“, 3-е издание, ст. 23 


\section{COMMON UNION OF EDUCATION AND CULTURE ORGANIZATIONS MANAGERS}

DODO CHUMBURIDZE

https://doi.org/10.35945/gb.2017.04.023

Doctor of Management (Art Management),

Associated Professor of Shota Rustaveli Theatre and Film Georgian State University, Georgia

KEYWORDS: EDUCATIONAL AND CULTURAL SPHERE, MODERN MANAGEMENT APPROACHES

\section{SUMMARY}

In this article we are talking about the relationship, which is typical for educational and cultural sphere. It is clear, that successful educational projects have positive impact on cultural sphere. On the development of the educational and cultural Sphere influences social, economic and political current factors in the country.

Manager must foresee the relationships and specification of educational and cultural sphere, which is prerequisite of education creative and self-actualize generation. For managers in cultural sphere for reaching successful result is helpful the Strengthen of educational projects.

Under The criteria of organizational success is considered the manager with experience, which has good knowledge of the specification of this sphere and owns modern management approaches. It should be noted, that the success of the organization is result of managerial decision. 